\title{
Assessment of COVID-19 Preventive Practice and Associated Factors Among Educators in Vietnam
}

\author{
Pham Le An $\mathbb{D}^{1,2}$, Giao Huynh $\mathbb{D}^{3}$, Han Thi Ngoc Nguyen $\mathbb{D}^{4}$, Pham Duong Uyen Binh $\mathbb{D}^{5,6}$, \\ Tam Thao Tuyet Tran', Tuong Vy Nguyen $\mathbb{D}^{2}$, Huong Thi Thu Vu ${ }^{3}$, Tuan Diep $\operatorname{Tran}^{7}$ \\ 'Family Medicine Training Center, University of Medicine and Pharmacy at Ho Chi Minh City, Ho Chi Minh City, Vietnam; ${ }^{2}$ Grant and Innovation \\ Center, University of Medicine and Pharmacy at Ho Chi Minh City, Ho Chi Minh City, Vietnam; ${ }^{3}$ Faculty of Public Health, University of Medicine and \\ Pharmacy at Ho Chi Minh City, Ho Chi Minh City, Vietnam; ${ }^{4}$ Infection Control Department, University Medical Center Ho Chi Minh City, Ho Chi \\ Minh City, Vietnam; ${ }^{5}$ Department of Educational Quality Assurance, University of Medicine and Pharmacy at Ho Chi Minh City, Ho Chi Minh City, \\ Vietnam; ${ }^{6} \mathrm{Graduate}$ School of Medicine, International University of Health and Welfare, Tokyo, Japan; ${ }^{7}$ Faculty of Medicine, University of Medicine and \\ Pharmacy at Ho Chi Minh City, Ho Chi Minh City, Vietnam
}

Correspondence: Giao Huynh, Faculty of Public Health, University of Medicine and Pharmacy at Ho Chi Minh City, 217 Hong Bang, District 5, Ho Chi Minh City, Vietnam, Tel +84908608338, Email hgiaoytcc@ump.edu.vn

Background: Educators play a critical role in offering knowledge that is vital to preventing the spread of the COVID-19 in educational settings. This study aims to assess the proportion of preventive practices towards COVID-19 and associated factors among educators in Vietnam.

Methods: A cross-sectional study was conducted on educators at the University of Medicine and Pharmacy at Ho Chi Minh City (UMP) using a self-administered questionnaire between June and August 2020. Online surveys and a multivariable logistic regression analysis were used to determine factors associated with practices. Adjusted odds ratio (AOR) and 95\% confidence interval (95\% CI) were performed using Stata 14.

Results: A total of 779 eligible participants were approached, most of them under 50 years (84.1\%), around three-fifth were female $(61.0 \%)$ and lecturers $(61.1 \%)$, with only $38.1 \%$ of them working at hospitals. Overall, the majority of participants had good preventive practices towards COVID-19 (88.6\%). Factors identified as being associated with good practices included participants who are lecturers (AOR 1.8, 95\% CI: 1.05-2.97), attending training courses related to COVID-19 (AOR 1.7, 95\% CI: 1.05-2.87), working at hospitals (AOR 2.5, 95\% CI: 1.28-4.76) and having a higher level of knowledge and attitude relating to COVID-19 (AOR 2.8, 95\% CI: 1.52-5.17; AOR 2.8, 95\% CI: 1.70-4.48, respectively) (all p < 0.05).

Conclusion: These findings revealed that most educators reported a good level of preventive practices towards COVID-19. However, lower levels of practices still exist towards COVID-19 among participants who were administrative staff and have less access to training courses related to COVID-19, who reported that they did not work at the hospital and had a lower level of knowledge and attitude related to COVID-19. Because of the important role of educators in the education system, this study is expected to help education and health authorities implement suitable interventions to fill the gaps in practices between educators.

Keywords: COVID-19, knowledge, attitude, practice, educator, Vietnam

\section{Introduction}

The emergence of the novel coronavirus disease 2019 (COVID-19) in Wuhan, China, in December 2019, caused the infection and deaths of millions of people, and new cases and deaths continue to be reported globally. ${ }^{1,2}$ In response to the COVID-19 situation, the World Health Organization (WHO) declared a Public Health Emergency of International Concern on January 30, 2020 and then the Pandemic on March 11, 2020 to urge all the countries around the world to take urgent and decisive action against the virus. ${ }^{3}$ Previous studies revealed that patients with comorbidities such as diabetes, hypertension, or respiratory disease are more susceptible to COVID-19 infection, which often results in a poor prognosis and higher likelihood of death. ${ }^{4}$ The swift spread of the COVID-19 virus around the world lead to the remarkable consequences such as a global economic crisis, which is predicted to continue to rise substantially. Many workers 
(including the self-employed) are now unemployed and weakened welfare safety nets, in many countries, further threaten health and social insecurity. ${ }^{5}$ Additionally, schools and universities have been closed for an extended period, with other social activities such as festivals, conferences and activities for large crowds having been mostly canceled. ${ }^{6}$

In Vietnam, after the first confirmed case was recorded on January 22, 2020, being an elderly man who entered the country from China, there were 1440 confirmed cases and 35 deaths reported in the year $2020 .{ }^{7,8}$ Although Vietnam was not one of the countries identified as having a high number of confirmed cases, the national outbreak was considered complex, and the unpredictability of the pandemic's scale was a potential threat to the country's healthcare system capabilities. Responding to the pandemic was considered an urgent mission through a combination of rigorous measures, such as local lockdowns, including apartment blocks, streets and communities, where infected cases emerged, isolating infected individuals, tracing and quarantining their contacts. The supply of vaccines and specific treatments has not proven to be effective at the time of the survey; therefore, it is essential to enhance routine precautionary behaviors among the public to respond to the disease, in particular, governments encouraging people to adhere to practices and behaviors through the $5 \mathrm{~K}$ message (washing hands, wearing masks, social distancing of at least 2 meters, disinfection and health declaration) to reduce the transmission capability of the virus.

Nevertheless, the effectiveness of COVID-19 preventative measures based on adherence and belief in the protectiveness of the measure as a whole from the community. Amidst the pandemic, the educating of precautionary behaviors, and mobilizing a health response force against COVID-19, may help prevent a public health emergency, protecting the population's vulnerability to catching the virus. It is important to investigate all factors relating to the disease, including adherence practice measures and education. Previous studies highlighted that people who engage in preventive behaviors, such as washing hands, wearing masks, maintaining social distance, etc., help reduce the potential morbidity and mortality of COVID-19. ${ }^{9}$ Besides, good practices have been essential to successfully control outbreaks in previous pandemics, such as severe acute respiratory syndrome SARS, ${ }^{10} \mathrm{H} 5 \mathrm{~N} 1,{ }^{11}$ swine flu, ${ }^{12}$ and H1N1. ${ }^{13}$ Studies of the COVID-19 pandemic conducted on different populations like health-care workers, ${ }^{14}$ students, ${ }^{15}$ and the general population ${ }^{16}$ showed that the supply of knowledge and a positive attitude helps to motivate individuals to adhere to preventive behaviors. Recent research in Vietnam revealed that the participants had adequate knowledge, a positive attitude and good practices towards COVID-19; however, the level of some practice measures were lower than that expected. ${ }^{17-20}$ By contrast, little was known about preventive practice relating to COVID-19 among educators. This is important because they play a paramount role in the education of students and colleagues to minimize the spreading of the virus. ${ }^{21}$ Also, previous studies indicated that teachers could be affected by their students' mental health, in particular, their attitudes and practices that affect the students. ${ }^{22}$ As a result, this study aims to assess that the rate of preventative practices towards COVID-19 and associated factors among educators in Vietnam, to develop and implement health education and communication interventions tailored to their needs.

\section{Methods}

\section{Study Setting}

This research was conducted in the University of Medicine and Pharmacy of Ho Chi Minh City (UMP), which is recognized as one of the two major medical teaching institutions in Vietnam. The University is composed of seven Faculties including Medicine, Pharmacy, Odonto-Stomatology, Fundamental Sciences, Nursing and Medical Technology, Traditional Medicine and Public Health. Additionally, the University recently opened its own Medical Center/Hospital, with over 650 beds, using modern medical equipment and highly qualified staff as a treatment, teaching and research facility.

\section{Study Design and Participants}

A descriptive cross-sectional study was performed using a self-administered questionnaire via an online survey between June and August 2020. From a list of all educators working at the University of Medicine and Pharmacy at Ho Chi Minh City, participants were recruited for this survey. A sample size was calculated by using the single population proportion formula. Because there was no published data that showed COVID-19 preventative practices among educators in Vietnam, $50 \%$ of the rate was used to get the maximum sample size by considering a margin of error of $5 \%$ and $95 \%$ 
confidence level. After considering a $30 \%$ non-response rate or having incomplete data, the minimum sample size was 550. However, all lecturers were invited to participate in this study but only responses received during the period from June to August 2020 were included. A total of 779 participants were included in the final analysis after excluding respondents who did not meet eligibility criteria (a response rate of $76.3 \%$ ).

\section{Inclusion and Exclusion Criteria}

All educators who were working at UMP during the time of the survey were recruited for this study. The exclusion criteria included duplicate questionnaires submitted by respondents with the same IP address, participants who failed to complete the survey after having received a maximum of four reminder emails and questionnaires recorded as missing items in the part of Knowledge, Attitude, Practice (KAP).

\section{Study Variables}

The main outcome variables of this research were the preventative practices towards COVID-19. Socio-demographic factors, knowledge towards COVID-19, attitudes towards COVID-19 were independent variables.

\section{Measures}

The structured questionnaire was developed following our previous study assessing the KAP towards COVID-19 among students in Vietnam. ${ }^{18}$ The questionnaire was pretested and we performed a reliability analysis before the actual data collection occurred, with the Cronbach's alpha coefficient of 0.88 , indicating good internal consistency. The questionnaire consisted of four parts, including baseline information and a set of questions to assess KAP towards COVID-19. Part 1 consisted of the socio-demographics of the participants including age ( $<50$ and $\geq 50$ years), gender (male, female), occupation (lecturer, administrative staff), working at the hospital (yes, no), living situation (with family/relatives, with friends, alone) and source of COVID-19 information (social media, websites of university/Health Ministry/WHO, training courses toward COVID-19, local government, relatives). Part 2 contained 6 questions relating to knowledge towards COVID-19 concerning the pathogens, transmission, common signs, treatment, prevention and people who have a high risk of severe illness and death. Each item was measured with two options of yes or no. For the evaluation, each yes answer is given one point whereas the no answer was recorded as zero. The overall knowledge score ranged from 0 to 6 and was divided into sufficient or insufficient knowledge. Respondents who achieved 5 points or higher were considered to have sufficient knowledge, and less than 5 being marked as an insufficient knowledge. ${ }^{18}$ Part 3 focused on attitudes towards COVID-19 was assessed by 8 questions, the scores were based on a 5-point Likert Scale ranged from strongly disagree to strongly agree. For each attitude item, the score was calculated into 1 point (strongly agree and agree) and 0 point (strongly disagree, neutral, disagree), the cut-off level of total attitude items 7 points or higher being considered as a positive general attitude, and less than 7 being marked as a negative general attitude. ${ }^{18}$ Part 4 included 8 yes or no questions for investigating practices. These questions mentioned preventive measures such as wearing masks, washing hands, social distancing, and according to Ministry of Health instructions, if a suspected COVID-19 infection is identified. Each yes answer is recorded at one point. The overall maximum possible score was 8 . After calculating the practices score, two groups were identified, being a good practice group with an overall score of 7 points or higher, whereas a score under 7 points was assigned as poor practices. ${ }^{18}$

\section{Operational Definition}

The sum score of each KAP outcome was assessed based on Bloom's cut-off point. ${ }^{23}$ The overall knowledge score was classified into a high-level of knowledge (80-100\%), a moderate level of knowledge (60-80\%), and a low-level of knowledge (less than 60\%). ${ }^{23}$ The overall attitude scores were categorized as positive attitude (80-100\%); neutral attitude $(60-80 \%)$ and negative attitude (less than $60 \%){ }^{23}$ The overall practice scores are categorized as good level ( $80-$ $100 \%$ ), fair level (60-80\%) and poor level (less than $60 \%)^{23}$

\section{Data Collection Procedures}

From a list of all educators at UMP, a letter was sent via personal email, to inform and enroll the participants in the study. All participants were informed that their participation was voluntary and completed the consent form before partaking in 
the survey. If the educators agreed to take part in the survey, they would be instructed to click on a link and access was granted by using private code to ensure information security. Every day, the main investigator checked and monitored the fulfillment and quality of the data collected. If participants did not respond to the survey, they received a maximum of four reminder emails.

\section{Statistical Analysis}

All data was entered and cleaned using Excel 2019 and analyzed using STATA 14 software. Descriptive analysis was reported as frequency, the percentage used for socio-demographics, items to assess knowledge, attitude, and practices. Chi-square was performed in the univariable analysis, and after that, variables with a p-value less than 0.05 were considered for the multivariable logistic regression analysis. In the multivariable logistic regression analysis, the Adjusted Odds Ratio (AOR) was recorded with a 95\% confidence interval (95\% CI), the significance level was set at $5 \%$ and was calculated to declare the statistically significant relationship between good practice and the independent variables. The model fitness was assessed by the Hosmer-Lemeshow test $(\chi 2=8.1,6$ degrees of freedom, $p=0.231)$ and indicated that the goodness of it was satisfactory. Multicollinearity of the independent variables was assessed by using Variance Inflation Factor (VIF) and the mean VIF was 1.16.

\section{Ethics Approval}

This study adhered to the Declaration of Helsinki. All participants voluntarily participated in this survey and all information is recorded as anonymous. Informed consent was obtained from all participants in the study. All procedures performed in this study involving participants followed the ethical standards of the Research Ethics Committee at the University of Medicine and Pharmacy at Ho Chi Minh City, Vietnam (No: 375/HĐĐĐ-ĐHYD signed on 02/06/2020).

\section{Results}

Among all 779 eligible participants, most of them were under 50 years old (84.1\%) and over three-fifths were female (61\%); Lecturers accounted for $61.1 \%$, and $38.1 \%$ worked at the hospital. The vast majority of them were living with family or relatives (84\%). Participants' sources of information in relation to COVID-19 were mainly websites of the University/Health Ministry/WHO (89.9\%), social media (83.4\%), and training courses provided by the university (53.9\%) (Table 1).

Table 2 describes the level of COVID-19 knowledge. In general, the majority of participants possessed sufficient knowledge about COVID-19 (89.9\%) and the response score to six questions about COVID-19-related knowledge ranged from $73.3 \%$ to $98.1 \%$, which showed that most of the participants knew essential facts, including COVID-19 was caused by SARS- CoV-2, transmission, common signs, and specific treatment medication.

The results relating to attitude categories are summarized in Table 3. Overall, $74.3 \%$ of participants reported a positive attitude towards COVID-19. The majority of them would accept isolation if they contracted COVID-19 (98.0\%), agreed that washing hands and wearing masks could prevent the transmission of COVID-19 (97.4\%), and believed that the health-care workforce and infection-control programs could help reduce the infection (95.9\%). Approximately $95 \%$ of them indicated that they would be willing to participate in a voluntary team to support the health force in Vietnam. They mostly accepted vaccinations, accounting for $85.2 \%$. However, just over half of those were concerned about getting the COVID-19 disease (65.3\%).

Table 4 illustrates practices toward COVID-19. Most of them had good practices, which stood at $88.6 \%$. Over $80 \%$ of the participants had appropriate hygiene habits, such as wearing masks, washing hands, social distancing, and, according to Ministry of Health, instructions should a person be suspected of a Covid-19 infection.

Table 5 reveals factors associated with practices regarding COVID-19. Statistically significant associations were found between occupation, working at the hospital, training courses in COVID-19, knowledge, attitudes and practices towards COVID-19 (all $\mathrm{p}<0.05$ ). In the multivariable logistic regression analysis, participants who were Lecturers, working at the hospital as well as had training courses in COVID-19, were more likely to have good practices over individuals who were administrative staff, did not work at the hospital and did not attend training courses related to COVID-19 (AOR 1.8, 95\% CI: 1.05-2.97), (AOR 2.5, 95\% CI: 1.28-4.76), (AOR 1.7, 95\% CI: 1.05-2.87), respectively, 
Table I Baseline Characteristics of Participants $(N=779)$

\begin{tabular}{|l|c|}
\hline Characteristics & $\mathbf{N}(\%)$ \\
\hline Age (years) & $655(84.1)$ \\
\hline$<50$ & $124(15.9)$ \\
\hline$\geq 50$ & \\
\hline Gender & $304(39.0)$ \\
\hline Male & $475(61.0)$ \\
\hline Female & \\
\hline Occupation & $476(61.1)$ \\
\hline Lecturer & $303(38.9)$ \\
\hline Administrative Staff & $232(29.8)$ \\
\hline Working at hospital & $165(21.2)$ \\
\hline Yes & $657(38.1)$ \\
\hline No & $682(61.9)$ \\
\hline Living situation & $654(8.5)$ \\
\hline With family/relatives & \\
\hline With friends & $(83.4)$ \\
\hline Alone & \\
\hline Source of COVID-19 information (yes) & \\
\hline Social media & \\
\hline Websites of University/Health Ministry/WHO & \\
\hline Training courses toward COVID-19 & \\
\hline Local government & \\
\hline Relatives & \\
\hline
\end{tabular}

Table 2 Knowledge Toward COVID-19 ( $\mathrm{N}=779)$

\begin{tabular}{|l|l|}
\hline Question (Correct Answer) & N (\%) \\
\hline Caused by SARS- CoV-2 (yes) & $648(83.2)$ \\
\hline Transmission by close contact with an infected person through droplets (yes) & 764 (98.1) \\
\hline Common signs (Fever or Cough or fatigue or sputum production or shortness of breath) (yes) & $750(96.3)$ \\
\hline Specific treatment medication (No) & 739 (94.9) \\
\hline Prevention of infection (Wear mask, hand washing, surfaces cleaning, keep distance from others) (yes) & 757 (97.2) \\
\hline People with chronic illness at high risk of severity and death (yes) & 571 (73.3) \\
\hline Knowledge (Sufficient) & 701 (89.9) \\
\hline
\end{tabular}


Table 3 Attitude Toward COVID-19 ( $\mathrm{N}=779)$

\begin{tabular}{|c|c|}
\hline Question & $\mathbf{N}(\%)$ \\
\hline I think I will probably get the illness & $509(65.3)$ \\
\hline I am worried one of my family members may get an infection & $578(74.2)$ \\
\hline If I get COVID-19, I will accept isolation in health facilities & $763(98.0)$ \\
\hline Transmission of COVID-19 can be prevented by washing hands with soap frequently and wearing masks & $759(97.4)$ \\
\hline $\begin{array}{l}\text { Prevalence of COVID-I } 9 \text { infection can be reduced by the active participation of health care workers in hospital } \\
\text { infection control programs }\end{array}$ & $747(95.9)$ \\
\hline If a COVID-19 vaccine was available, I would have it & $664(85.2)$ \\
\hline COVID-19 patients should be kept in isolation & $697(89.5)$ \\
\hline I am ready to participate in the team to volunteer to support the health force & $738(94.7)$ \\
\hline Attitude (Positive) & $579(74.3)$ \\
\hline
\end{tabular}

Table 4 Practices of Educators Toward COVID-19 ( $\mathrm{N}=779)$

\begin{tabular}{|l|c|}
\hline Question (Correct Answer) & N (\%) \\
\hline Wearing mask cover my mouth and nose (yes) & $710(91.1)$ \\
\hline Avoiding unnecessary travel and staying away from large groups of people (yes) & $679(87.2)$ \\
\hline Washing hands frequently (yes) & $705(90.5)$ \\
\hline Washing hands with soap and water or alcohol hand sanitizer (yes) & $709(91.0)$ \\
\hline Average time for washing hands $\geq 20$ seconds (yes) & $690(88.6)$ \\
\hline Adherence to social distancing according to the Ministry of Health's instructions (yes) & $717(92.0)$ \\
\hline Wearing masks when in public or when exposed to others (yes) & $709(91.0)$ \\
\hline Following the guidelines of the Ministry of Health if a suspected Covid-19 infection is reported (yes) & $724(92.9)$ \\
\hline Practice (Good) & $690(88.6)$ \\
\hline
\end{tabular}

all $\mathrm{p}<0.05$. Besides, individuals who recorded a sufficient level of knowledge and a positive attitude regarding COVID19 were also more likely to have good preventive practices (AOR 2.8, 95\% CI: $1.52-5.17$ ) and (AOR 2.8, 95\% CI: 1.70 4.48), respectively, all $\mathrm{p}<0.001$. (Table 6).

\section{Discussion}

The outbreak of COVID-19 has threatened global public health and had a disastrous socio-economic impact around the world. Vietnam has been experiencing an ongoing battle with the virus and has been confronted with a public health emergency. Strict measures have been applied across the nation including lockdown, community quarantining, banning travel (domestic and international), social distancing measures and closing of schools/universities and workplaces. Public health education is considered an effective measure to limit and control the pandemic spreading. ${ }^{6}$ Nevertheless, it will require the public to have appropriate knowledge, possess a positive attitude and adhere to desired practices. Therefore, this study investigated the proportion of preventive practices toward COVID-19 and associated factors among educators in Vietnam to provide insight that will assist in the implementation and design of future effective public health interventions for these subjects. 
Table 5 Results of Logistic Regression Factors Associated with Practice Regarding COVID-19 (N = 779)

\begin{tabular}{|c|c|c|c|}
\hline \multirow[t]{2}{*}{ Variables } & \multicolumn{2}{|c|}{ Practice Toward COVID-I9 } & \multirow[t]{2}{*}{$\mathbf{p}$} \\
\hline & $\begin{array}{l}\text { Good, n (\%) } \\
690(88.6 \%)\end{array}$ & $\begin{array}{c}\text { Poor, n (\%) } \\
89(11.4 \%)\end{array}$ & \\
\hline \multicolumn{4}{|l|}{ Age (years) } \\
\hline$<50$ & $579(83.9)$ & $76(85.4)$ & 0.719 \\
\hline$\geq 50$ & $111(16.1)$ & $13(14.6)$ & \\
\hline \multicolumn{4}{|l|}{ Gender } \\
\hline Male & $262(37.9)$ & $42(47.2)$ & 0.093 \\
\hline Female & $428(62.1)$ & $47(52.8)$ & \\
\hline \multicolumn{4}{|l|}{ Occupation } \\
\hline Lecturer & $440(63.8)$ & $36(40.5)$ & 0.000 \\
\hline Administrative staff & $250(36.2)$ & $53(59.5)$ & \\
\hline \multicolumn{4}{|l|}{ Working at hospital } \\
\hline Yes & $282(40.9)$ & $15(16.9)$ & 0.000 \\
\hline No & $408(59.1)$ & $74(83.1)$ & \\
\hline \multicolumn{4}{|l|}{ Living situation } \\
\hline With family/relatives & $582(84.4)$ & $72(80.9)$ & \\
\hline With friends & $59(8.6)$ & $7(7.9)$ & 0.380 \\
\hline Alone & $49(7.0)$ & $10(11.2)$ & \\
\hline \multicolumn{4}{|l|}{ Source of COVID-19 information (yes) } \\
\hline Social media & $576(88.6)$ & $74(11.4)$ & 0.937 \\
\hline Websites of University/Health Ministry/WHO & $622(88.7)$ & $79(11.3)$ & 0.683 \\
\hline Training courses toward COVID-19 & $389(92.6)$ & $31(7.4)$ & 0.000 \\
\hline Local government & $212(91.4)$ & $20(8.6)$ & 0.109 \\
\hline Relatives & $147(89.1)$ & $18(10.9)$ & 0.815 \\
\hline \multicolumn{4}{|l|}{ Knowledge } \\
\hline Sufficient & $636(92.2)$ & $65(73.0)$ & 0.000 \\
\hline Insufficient & $54(7.8)$ & $24(27.0)$ & \\
\hline \multicolumn{4}{|l|}{ Attitude } \\
\hline Positive & $533(77.3)$ & $46(51.7)$ & 0.000 \\
\hline Negative & $157(22.8)$ & $43(48.3)$ & \\
\hline
\end{tabular}

Generally, we found that most participants took good precautions to prevent COVID-19 such as wearing masks, washing hands, adhering to social distancing according to Ministry of Health instructions (over $80 \%$ ). These results were consistent with previous studies. ${ }^{15,17,18}$ These findings have revealed that most educators had good practices related to COVID-19 during the outbreak, which indicated that effective education was delivered by massive public education 
Table 6 Multivariable Logistic Regression Factors Associated with Practice Regarding COVID-19 (N = 779)

\begin{tabular}{|c|c|c|c|c|}
\hline \multirow[t]{2}{*}{ Variables } & \multicolumn{2}{|c|}{ Practice Toward COVID-19 } & \multirow[t]{2}{*}{$\mathbf{p}$} & \multirow[t]{2}{*}{ Adjusted OR $(95 \% \mathrm{Cl})$} \\
\hline & $\begin{array}{l}\text { Good, n (\%) } \\
690(88.6 \%)\end{array}$ & $\begin{array}{l}\text { Poor, n (\%) } \\
89 \text { ( } 11.4 \%)\end{array}$ & & \\
\hline \multicolumn{5}{|l|}{ Occupation } \\
\hline Lecturer & $440(63.8)$ & $36(40.5)$ & 0.031 & $1.8(1.05-2.97)$ \\
\hline Staff & $250(36.2)$ & $53(59.5)$ & & \\
\hline \multicolumn{5}{|c|}{ Working at hospital } \\
\hline Yes & $273(39.6)$ & $24(26.9)$ & 0.007 & $2.5(1.28-4.76)$ \\
\hline No & $417(60.4)$ & $65(73.1)$ & & \\
\hline \multicolumn{5}{|c|}{$\begin{array}{l}\text { Training courses for } \\
\text { COVID-19 }\end{array}$} \\
\hline Yes & $389(56.4)$ & $31(34.8)$ & 0.031 & $1.7(1.05-2.87)$ \\
\hline No & $301(43.6)$ & $58(65.2)$ & & \\
\hline \multicolumn{5}{|l|}{ Knowledge } \\
\hline Sufficient & $636(92.2)$ & $65(73.0)$ & 0.001 & $2.8(1.52-5.17)$ \\
\hline Insufficient & $54(7.8)$ & $24(27.0)$ & & \\
\hline \multicolumn{5}{|l|}{ Attitude } \\
\hline Positive & $533(77.3)$ & $46(51.7)$ & 0.000 & $2.8(1.70-4.48)$ \\
\hline Negative & $157(22.8)$ & $43(48.3)$ & & \\
\hline
\end{tabular}

Notes: Hosmer and Lemeshow: $\mathrm{N}=779 ; \chi^{2}=8.1 ; \mathrm{df}=6 ; \mathrm{p}=0.23 \mathrm{I} ;$ Mean VIF $=1.16$.

strategies. However, some issues need to be considered that address gaps in the educational preparation among educators to help them stay safe and effective in the fight against COVID-19. Our investigation showed that educators who were Lecturers, working at the hospital and attending training courses related to COVID-19, were more likely to practice prevention techniques than others. This also accords with earlier observations, which showed that those who received education, ${ }^{14,24,25}$ and had access to training about the disease, reported significantly better knowledge and practices. ${ }^{15}$ Moreover, Lecturers need to understand precautionary behaviors to minimize the spreading of the virus as well as look for information to train their students and others at the college. Besides, the public health messaging of COVID-19 needs to be improved to deal with gaps in practices identified in administrative staff.

In terms of knowledge, the findings of educators resemble a prior study, conducted in students, with most of them having good knowledge in relation to pathogens, transmission, common signs, specific medication and measures of prevention. ${ }^{18}$ Moreover, the overall knowledge was higher than the results reported in Chen H's study, who found that only $63.7 \%$ of teachers had good knowledge. ${ }^{26}$ The difference in the level of knowledge is explained by applying different items relating to COVID-19, as well as participants in our study were educators of the main workforce for the healthcare system in the pandemic. These findings suggest that there is effective communication at the UMP and providing training must continue in order to adequately equip all educators with the knowledge to play their role in the fight against COVID-19. Besides, knowledge towards COVID-19 was significantly associated with prevention practices. This finding is in line with previous studies. ${ }^{14,18}$ The results revealed the importance of improving the provision of appropriate information and health literature for the behavior of educators, not only during the initial outbreak but also during the subsequent period of the pandemics' life. $^{26}$ 
Regarding attitude, these results revealed that the majority of participants had a positive attitude towards COVID-19, which is in accordance with previous findings, ${ }^{17,18}$ and thus this could be related to the effectiveness of controlling the pandemic in Vietnam. ${ }^{6}$ Findings found that most educators would be willing to participate in a team volunteering to support the health system, which showed optimistic signals in the context of the growing shortage of health-care workers across health-care disciplines, whereas educators helped serve as a front-line force against the pandemic. However, there were still participants who showed a negative attitude about getting the COVID-19 disease (65.3\%). This result is consistent with a previous study that showed health-care workers having a perceived high susceptibility and severity to COVID-19. ${ }^{20}$ Moreover, attitude towards COVID-19 was significantly associated with prevention practices. This finding is in line with previous studies. ${ }^{14,18}$ This suggested that implementing additional training, as well as supplying adequate personal protective equipment (PPE), can facilitate an optimistic belief that educators are working in a safe environment and they would not be infected.

This study has some limitations that should be acknowledged. First, the invited population only consisted of educators from a single university which may not be representative of all educators in Vietnam. Second, a cross-sectional study was performed to collect the data, and participants answered online which might include information bias.

\section{Conclusion}

These findings revealed most educators have gained a good level of preventative practices towards COVID-19. However, lower levels of practices still exist towards COVID-19 among participants who were administrative staff and has less access to training courses related to COVID-19, did not work at the hospital and had a lower level of knowledge and attitude related to COVID-19. Because of the important role of educators in the education system, this study is expected to help education and health authorities implement suitable interventions to overcome the gaps in practices between educators. Besides, it is a requirement to continue with additional education and training strategies to enhance preventive practices towards the pandemic for all educators, especially to deal with gaps in practices identified in the administrative staff.

\section{Data Sharing Statement}

The data set used and analyzed during the current research is available from the corresponding author on a reasonable request.

\section{Acknowledgments}

We thank the educators at the University of Medicine and Pharmacy at Ho Chi Minh City (UMP) for the time and effort they devoted to this study. The authors thank Raymond A Kuschert for assisting in translation.

\section{Author Contributions}

All authors made a significant contribution to the work reported, whether that is in the conception, design of the study, execution, acquisition of data, analysis and interpretation, or in all these areas; took part in drafting, revising or critically reviewing the article; gave final approval of the version to be published; have agreed on the journal to which the article has been submitted; and agreed to be accountable for all aspects of the work.

\section{Funding}

This research did not receive any specific grant from funding agencies in the public, commercial, or not-for-profit sectors.

\section{Disclosure}

The authors declare that they have no conflicts of interest for this work.

\section{References}

1. Li Q, Guan X, Wu P, et al. Early transmission dynamics in Wuhan, China, of novel coronavirus-infected pneumonia. N Engl J Med. 2020;382 (13):1199-1207. doi:10.1056/NEJMoa2001316

2. WHO. WHO coronavirus (COVID-19) dashboard. Available from: https://covid19.who.int/. Accessed November 18, 2021. 
3. WHO. Timeline: WHO's COVID-19 response. Available from: https://www.who.int/emergencies/diseases/novel-coronavirus-2019/interactivetimeline\#! Accessed November 18, 2021.

4. Gold MS, Sehayek D, Gabrielli S, Zhang X, McCusker C, Ben-Shoshan M. COVID-19 and comorbidities: a systematic review and meta-analysis. Postgrad Med. 2020;132(8):749-755. doi:10.1080/00325481.2020.1786964

5. Ahmed F, Ahmed N, Pissarides C, Stiglitz J. Why inequality could spread COVID-19. Lancet Public Health. 2020;5(5):e240. doi:10.1016/S24682667(20)30085-2

6. Nguyen TV, Dai Tran Q, Phan LT, et al. In the interest of public safety: rapid response to the COVID-19 epidemic in Vietnam. BMJ Global Health. 2021;6(1):e004100. doi:10.1136/bmjgh-2020-004100

7. Phan LT, Nguyen TV, Luong QC, et al. Importation and human-to-human transmission of a Novel Coronavirus in Vietnam. $N$ Engl $J$ Med. 2020;382(9):872-874. doi:10.1056/NEJMc2001272

8. WHO. Weekly epidemiological update - 29 December 2020. Available from: https://www.who.int/publications/m/item/weekly-epidemiologicalupdate-29-december-2020. Accessed November 18, 2021.

9. Anderson RM, Heesterbeek H, Klinkenberg D, Hollingsworth TD. How will country-based mitigation measures influence the course of the COVID-19 epidemic? Lancet. 2020;395(10228):931-934. doi:10.1016/S0140-6736(20)30567-5

10. Leung GM, Quah S, Ho LM, et al. A tale of two cities: community psychobehavioral surveillance and related impact on outbreak control in Hong Kong and Singapore during the severe acute respiratory syndrome epidemic. Infect Control Hosp Epidemiol. 2004;25(12):1033-1041. doi: $10.1086 / 502340$

11. Lau JT, Kim JH, Tsui HY, Griffiths S. Anticipated and current preventive behaviors in response to an anticipated human-to-human H5N1 epidemic in the Hong Kong Chinese general population. BMC Infect Dis. 2007;7:18. doi:10.1186/1471-2334-7-18

12. Rubin GJ, Amlôt R, Page L, Wessely S. Public perceptions, anxiety, and behaviour change in relation to the swine flu outbreak: cross sectional telephone survey. BMJ. 2009;339:b2651. doi:10.1136/bmj.b2651

13. Lin Y, Huang L, Nie S, et al. Knowledge, attitudes and practices (KAP) related to the pandemic (H1N1) 2009 among Chinese general population: a telephone survey. BMC Infect Dis. 2011;11:128. doi:10.1186/1471-2334-11-128

14. Tsegaye D, Shuremu M, Oljira D, Dubale S, Befekadu G, Bidira K. COVID - 19 related knowledge and preventive practices early in the outbreak among health care workers in selected public health facilities of Illu aba Bor and Buno Bedelle zones, Southwest Ethiopia. BMC Infect Dis. 2021;21 (1):490. doi:10.1186/s12879-021-06218-0

15. Zhang J, Yin Y, Dean J, et al. Knowledge, attitude, and practice survey of COVID-19 among healthcare students during the COVID-19 outbreak in China: an online cross-sectional survey. Front Public Health. 2021;9:742314. doi:10.3389/fpubh.2021.742314

16. Lee M, Kang B, You M. Knowledge, attitudes, and practices (KAP) toward COVID-19: a cross-sectional study in South Korea. BMC Public Health. 2021;21(295):2021. doi:10.1186/s12889-021-10285-y

17. Huynh G, Nguyen TN, Tran VK, Vo KN, Vo VT, Pham LA. Knowledge and attitude toward COVID-19 among healthcare workers at District 2 Hospital, Ho Chi Minh City. Asian Pac J Trop Med. 2020;13(6):260-265. doi:10.4103/1995-7645.280396

18. Le An P, Huynh G, Nguyen HTN, et al. Knowledge, attitude, and practice towards COVID-19 among healthcare students in Vietnam. Infect Drug Resist. 2021;14:3405-3413. doi:10.2147/IDR.S328677

19. Huynh G, Nguyen MQ, Tran TT, et al. Knowledge, attitude, and practices regarding COVID-19 among chronic illness patients at outpatient departments in Ho Chi Minh City, Vietnam. Risk Manag Healthc Policy. 2020;13:1571-1578. doi:10.2147/RMHP.S268876

20. Huynh G, Tran TT, Nguyen HT, Pham LA. COVID-19 vaccination intention among healthcare workers in Vietnam. Asian Pac J Trop Med. 2021;14 (4):159-164. doi:10.4103/1995-7645.312513

21. Chai CS, Merry R. Teachers' perceptions of teaching and learning in a knowledge-building community: an exploratory case study. Learn Media Technol. 2006;31(2):133-148. doi:10.1080/17439880600756670

22. Noble RN, Heath N, Krause A, Rogers M. Teacher-student relationships and high school drop-out: applying a working alliance framework. Can J Sch Psychol. 2021;36(3):221-234. doi:10.1177/0829573520972558

23. Seid MA, Hussen MS. Knowledge and attitude towards antimicrobial resistance among final year undergraduate paramedical students at University of Gondar, Ethiopia. BMC Infect Dis. 2018;18(1):312. doi:10.1186/s12879-018-3199-1

24. Lowcock EC, Rosella LC, Foisy J, McGeer A, Crowcroft N. The social determinants of health and pandemic H1N1 2009 influenza severity. Am J Public Health. 2012;102(8):e51-8. doi:10.2105/AJPH.2012.300814

25. Lau LL, Hung N, Go DJ, et al. Knowledge, attitudes and practices of COVID-19 among income-poor households in the Philippines: a cross-sectional study. J Glob Health. 2020;10(1):011007. doi:10.7189/jogh.10.011007

26. Chen H, Zhang M, Su L, et al. Knowledge, attitudes, and practices toward COVID-19 among Chinese teachers, Shenzhen: an online cross-sectional study during the global outbreak of COVID-19. Front Public Health. 2021;9:706830. doi:10.3389/fpubh.2021.706830

Infection and Drug Resistance

Dovepress

\section{Publish your work in this journal}

Infection and Drug Resistance is an international, peer-reviewed open-access journal that focuses on the optimal treatment of infection (bacterial, fungal and viral) and the development and institution of preventive strategies to minimize the development and spread of resistance. The journal is specifically concerned with the epidemiology of antibiotic resistance and the mechanisms of resistance development and diffusion in both hospitals and the community. The manuscript management system is completely online and includes a very quick and fair peer-review system, which is all easy to use. Visit http://www.dovepress.com/testimonials.php to read real quotes from published authors.

Submit your manuscript here: https://www.dovepress.com/infection-and-drug-resistance-journal 